Marketing in Asia Group

\title{
The Effects of Construal Level and Donation Magnitude: The Case of Cause-Related Marketing
}

\author{
Phang Ing @ Grace \\ Faculty of Business, Economics \& Accounting, Universiti Malaysia Sabah, Malaysia
}

Lin Hsin-Yin

Waseda University, Japan

Lim Tze-Yin

Faculty of Business, Design \& Arts, Swinburne University of Technology, Malaysia

\begin{abstract}
Marketers are focusing on their corporate social responsibility in recent years, utilizing charity business as an effective sale and marketing strategy. A better understanding of consumer behaviour in relation to cause-related marketing (CRM) is critical, as both marketers and consumers are able to build a win-win relationship. Borrowing the construal level theory, we examined the effects of advertising framing in CRM, focusing on how construal level and donation magnitude could have affected consumer's attitude and willingness to donate. The study proposes that words induce high construal level that consumers should have higher buying intention and willingness to participate in a word- vs. picture-based advertisement. Consistent with the previous study, the preliminary study had successfully attributed picture vs. words to low vs. high construal level. However, the main study results failed to indicate a higher intention to participate and to buy among consumers in a high (e.g. $25 \%$ of the selling price) vs. low donation magnitude (e.g. $5 \%$ of the selling price) condition. The contribution of the current study is expected to extend the construal level theory by assessing the donation magnitude, which affecting consumer behaviour in the marketing context. The findings of the studies added to the understanding of construal level and donation magnitude manipulations in CRM, which benefits both the CRM marketers as well as the academic researchers. Besides, this study also demonstrated the potential to develop brand awareness, promote a social cause and inspire consumers to demonstrate support for causes they concern about.
\end{abstract}

Keywords: Advertising, Construal Level, Donation Magnitude, Cause-Related Marketing, Corporate Social Responsibility, Consumer Behaviour

Publication Details: Received 5 Aug 2020; Revised 20 Nov 2020; Accepted 13 Dec 2020 


\section{Introduction}

Cause-related marketing (CRM) is categorized as a type of company sponsorship which involves both profit-motivated giving as well as socially responsible means to non-profit organizations (Bergkvist \& Zhou, 2019; Grau \& Folse, 2007). Despite its popularity, the other CRM researchers presented mix findings in relation to the effectiveness of CRM campaigns. As consumers generally request more transparency and corporate governance, their responses to CRM activities depend on the perceived firm motives (Cambell \& Kirmani, 2008; Cone, 2007; Ellen et al., 2000; Ndasi \& Akcay, 2020; Webb \& Mohr, 1998 in Folse, Niedrich \& Grai, 2010). Consumers question the genuineness of firm's involvement (Ellen et al., 2000), in which firms will be viewed as socially responsible when their perceived motives are altruistic (Folse et al., 2010). Whenever consumers fail to attribute CRM activities to altruistic motives, the CRM sponsorship will be assigned to self-serving motives (Folse et al., 2010). Previous CRM studies also tie higher donation magnitude to more altruistic motive (Folse et al., 2010; Grau, Garretson \& Pirsch, 2007) as the amount of the donations, in both monetary and magnitude terms, provides incentives for consumers (Becker et al., 2019; Folse et al., 2010) and affects CRM participation and intention to buy (Boenigk \& Schuchardt, 2013; Folse et al., 2010; Yoo \& Doh, 2018.). In fact, consumers were found to prefer donation magnitude over a price discount of the same dollar amount, varied by the level of donation (Strahilevitz, 1999).

Borrowing construal level theory, we examined the effects of advertising framing in CRM, focusing on how construal level and donation magnitude could have affected consumers' attitude and behavioural intentions to donate and to participate. Construal level theory proposes that people construe things differently based on their perceived psychological distance. A higher level of construal was experienced when events are far from me, here, and now (Kalkstein, 2017; Trope and Liberman, 2010). Previous studies showed that psychological distance influences how people think, feel and get motivated (Trope and Liberman, 2010; van Boven et al., 2010; Kivetz, Urminsky \& Zheng, 2006). High construal level is related to more abstract and central features, broader categorization and heightens concern for cause and feasibility of event; while low construal level leads to more concrete and secondary features and heighten concern for the consequences and functionality of an event (Trope \& Liberman, 2003; Liberman \& Forster, 2009; 2010; Rim, Amit, Fujita, Halbeisen \& Trope, 2015; Trope \& Liberman, 2010; Trope, Liberman, \& Wakslak, 2007).

The previous research indicates that even though there are exceptions (e.g. onomatopoeia and abstract art; Rim et al., 2015), words generally promote 'thinking of events in terms of their abstract and central features' and 'pictures promote thinking in terms of more concrete and idiosyncratic features'. Rim et al., (2015) also argue on how these mediums affect the way people think and process about a piece of information, or even prompt systematic differences in prediction, judgment, decision making and behaviours (Amit, Algom \& Trope, 2009; Gilead, Trope, \& Liberman, 2017). People in an abstract mindset will prefer verbal (vs. pictorial) thinking in a psychological distant condition (e.g. temporally, spatially, socially and proximal others) on object identification, categorization, and selective attention tasks (Amit, Wakslak \& Trope, 2013). Unfortunately, there is a dearth of research examining the original role of pictures and words as means of representation (Amit et al, 2009). 
As all objects can be represented with words or pictures, each type of representation is best suited to signify the referent object under selective conditions (Amit et al., 2009). We then speculate that under the right combination of donation magnitude and construal level manipulation, consumers will portray a higher intention to buy and to participate in the CRM activities. This paper further argues that the advertising medium, such as the usage of word vs. picture-based advertisements, will promote different levels of construal and lead to distinct behavioural intentions when paired with either high or low donation magnitude. A total of two main studies were carried out to test the proposed hypotheses, with two pre-tests designed to validate the effectiveness of construal level and donation magnitude manipulations.

\section{Literature Review}

Put aside the monetary with the financial trade-off, consumer choice for CRM products tend to increase when the donation amount increases (e.g. for non-monetary, monetary or combination CRM strategies; Muller, 2014). Donation magnitude, either high or low, affected consumer evaluations (e.g. high vs. low donation magnitude). In Grau et al.'s (2007) study, for instance, donation magnitude was found to affect credibility evaluation of the CRM campaign, with lesser donation magnitude leads to a greater distrust of the campaign. Boenigk and Schuchardt's (2013) study on CRM for luxury brand indicated greater willingness to purchase for the lower price product (\$180) in the case of a high donation magnitude (25\% of the selling price) than when it is low (1\% of the selling price). When the minimum purchase volume was held constant, donation magnitude affects the participation intention (Becker, et al., 2019; Folse et al., 2010). This understanding is shared later by Ndasi and Ackay (2020) in their study of authenticity in digital cause-related advertising, in which donation magnitude is proved to be a stronger determinant than ad-context congruence in influencing authenticity. Even if it is viewed as a persuasive tactic, Folse et al. argued that it could still be well-received by consumers as long as it lies within the acceptance range of donation. A higher level of donation magnitude should induce a greater willingness to participate and to buy. Hence,

H1 In CRM, a high donation magnitude should receive higher evaluations than a low donation magnitude.

In their studies on construal level, Wiliams, Stein and Galguera (2014) argued the differences between 'psychological distance' and 'construal level' in influencing emotional evaluation. While psychological distance reduces the intensity of the sense of sympathy people have towards those who receive the donation, abstract interpretation idealized the act of donation. In other words, it is more effective to promote altruistic behaviours by promoting the central reasons in which inducing the abstract interpretation of such behaviours (high construal level). Based on the argument, picture, and word-based advertisement in a CRM campaign should and will generate different construal levels. Rim et al. (2015) in their studies, argued that high level, central features are more representing in a distal event, while proximal events represent low level, peripheral features. When consumers think about 'why' they donate vs. 'how' they donate, they adopt a higher construal level. In doing so, word (vs. picture) priming leads to greater global (vs. local) processing of subsequent 
perceptual information, which further leads to more categorical (rather than exemplar) related thoughts (Kalkstein, 2017; Rim et al., 2015).

Amit et al. (2009) identified four points that differ picture from words, (a) in whether there are similar physical features with the referent object, (b) the adoption of perceptual analysis, (c) in the referents' set-size, and (d) the cognitive organization of the represented stimuli. Generally, pictures are "icons, analogue representation of specific objects in a definite time and place" (Rim et al., 2015). Due to resemblance to the represented object, they provide a snapshot of a situation that elaborate on the details of a situation, similar to a low construal level (e.g. particular, contextual, and concrete representations). Assigning a word to an object is synonym with placing the object in a semantic category that conferral meanings (Amit et al., 2009). Amit et al. (2009) hence suggest to utilize pictures to represent distal objects, and words for proximal objects as higher preferences should follow (Amit et al., 2013). Therefore, cause-related marketing is viewed as a type of altruistic activity, in which word-based advertisement is proposed to induce a higher construal level and represents the gist of the campaign better than the picture-based advertisement. Hence,

H2 In the evaluation of a CRM related advertisement, the word-based advertisement should receive higher evaluations than the picture-based advertisement.

A person with a higher construal level focuses more on the desirability aspects; meanwhile, feasibility aspects are more attractive to the lower construal level individuals (Liberman \& Trope, 1998). In the study of words vs. picture, Rim et al. (2015) explain the usage of a picture in enhancing the practicality consideration and word consideration induces more idealism of a decision. Besides, a tendency to donate becomes clearer when the subject thinks about the abstract reason (why donate) rather than the way to donate (how to donate; William et al., 2014). Psychological distance reduces the intensity of effect while the construal level shifts the valence (positive vs. negative) of one's thoughts (Kalkstein, 2017; William et al., 2014). In the case of CRM, the abstract construal positively shifts the valence of experiences, hence improving the evaluation for both positive and negative experiences (William et al., 2014) and higher willingness to participate and to buy should be followed. As such, the choice of the message delivery medium plays an important role in affecting people's donation preferences (Fujita, Eyal, Chaiken, \& Trope, 2008).

Hence, it is proposed that people with a high construal level (those who are shown in word ads) will focus on the idealism/desirability of the CRM campaign, such as "I would like to contribute to the CRM effort". As their high construal level are dealing with the pleasant experiences of the donation, and focus more on the consideration of "join or not join" rather than be influenced by the CRM donation amount. Contradictory, those with a lower construal level (those who are shown in picture ads) will adopt a more practical consideration, such as "how much will be the donation?" and "will the company benefited from the CRM campaign?". By considering these issues, people are concerned with the details of the purchase and the campaign, hence are more sensitive to the amount of the donation. As a result, their willingness to participate and to buy will differ according to the level of donation amounts. 
H3 Those in the picture-based advertisement will be more sensitive towards the donation magnitude than the group with a word-based advertisement.

H4 Those in the picture-based advertisement will not significantly differ in terms of their willingness to participate and to buy in both high and low donation magnitude conditions.

The previous studies suggested that the donation amount influences perceived credibility, which further increases the willingness to participate in a CRM campaign. In this paper, a word-based advertisement is proposed to induce a higher construal level and represents the gist of the campaign better than the picture-based advertisement (Yan, Sengupta \& Hong, 2016). Validated by William et al.'s (2014) study, a high level of construal will encourage more donations. In other words, we would expect that consumers to have the most favourable evaluations in a word-based with high donation magnitude (e.g. 25\%) condition.

H5 In a CRM campaign, a word-based $\mathrm{x}$ high donation magnitude advertisement should receive highest evaluation.

\section{Research Methodology}

\section{Pre-Test 1}

Pre-test 1 was carried out to identify the suitable combination of the corporate brand and charitable organizations and to ensure the translated questionnaire was clearly understand by Japanese respondents. Three established corporate brands were. As CRM is more likely to impact frivolous brands than the utilitarian brands (Pracejus \& Olsen, 2004), the three shortlisted corporate brands were Apple Inc., Tokyo Disneyland and Starbucks which are highly familiar to Japanese consumers, shortlisted from both the Nikkei BP Consulting's report on Brand Japan 2014 and Forbes' World's Most Reputable Companies 2014. Meanwhile, three charitable organizations namely Red cross Society Japan (RSJ), World Wildlife Fund (WWF) and Save the Children (STC) were chosen based on the Charity Navigator's ranking of American charitable organizations in Japan. Each of these six individual companies and their nine combinations was tested separately for their perceived familiarity and preferences, and also willingness to donate. An established online research company (Micromill) was engaged in the collection of samples, based on Japan's population distribution (e.g. age, gender, occupation). A total of 100 valid questionnaires was collected from a total of 135 distributed, with equal gender distribution for the ninecorporate brand-charitable organization pairs.

The CRM evaluation refers to the overall positive feeling that the consumers have towards a particular cause organization (e.g. in this case, charitable organization; Ross, Patterson \& Stutts, 1992). As these measurement items were adopted from western literature, the items have proceeded for reliability checking. Measurement of the consumer familiarity towards both the corporate brand and charity organization's involvement in CRM utilized Simonin and Ruth's (1998) 3 item-7-point familiarity scale. The respondents' general attitudes toward the organization were measured using Nan and Hao's (2007) 3 item-7-point scale. Finally, the respondents' 
willingness to donate money was measured with Bennett, Kim and Loken's (2013) 2 item-7-point scale. The results of the pre-test indicated that consumers were most aware of Disney brand compared to other two corporate brands. The examination on the nine pairs of the corporate brand-charitable organization indicated that the Tokyo Disneyland-WWF pair had the highest scores. To enhance the realism of the advertisement, Disney-WWF pair was chosen based on Disney's past involvement in many environment protection activities.

\section{Pre-Test 2}

Rim et al. (2015) argued that people evaluate word vs. picture message differently due to different construal level representations. The framing of words vs. pictures showed that the processing of word message should be of higher-level construal than the processing of picture message, due to the differences in mindset (e.g. high vs. low construal levels). Consistent with Rim who utilized single words or simple pictures only, this study utilized brand names (in words) and logos (in the picture) which were common strategies used in a CRM advertisement. Tokyo Disneyland and WWF Japan pair was selected from pre-test 1 . Due to trademark consideration, the actual company logo will not be used later in the main study. It is, therefore, necessary to test the influence of brand logo (e.g. in words and in pictures) on respondents' construal levels prior to the testing of word vs. picture effects (i.e. in an advertisement).

The respondents were undergraduate and postgraduate students in two well-known universities in Greater Metropolitan of Tokyo who were willing to take part in the study. 109 valid questionnaires were collected from a total of 116 respondents (male $=57$, female $=52$ ). First of all, the respondents were randomly assigned to the two manipulation groups, with group A for picture-based and group B for word-based framing. The respondents examined twenty corporate brands (same corporate brands with Group A in the picture and group B in word) in silence for two minutes and later categorized these corporate brands into different product categories based on perceived similarities (e.g. Food and beverages, automotive, entertainment, banking services etc., refer to Figure 1). They were then asked to repeat the same procedure for another set of 20 corporate brands to enhance the priming effect, which total to 40 corporate brands examined.

After the priming procedure, the respondents filled in the Japanese version of Behaviour Identification Form (BIF) in relation to construal level measurement, utilized by Moriguchi, Abe, Onzo, Yashima and Togawa (2014). The BIF scores range from 0-25, with score approaching 25 considered as high construal level. The ttest results indicated a significant difference between Group $A(n=55$, mean $A=$ 10.60) and Group $B(n=55$, mean $B=12.981), t=-3.016, p=.003$. The results of the BIF test supported the proposed hypothesis. Generally, respondents in Group B has significantly higher BIF scores than those in Group A. In particular, the respondents who were shown only the brand name in words (Group B) were successfully framed in a high construal level; meanwhile, those with logos (in the picture, Group A) were framed in a low construal level. Extended the previous studies, the results indicated that the evaluation of logo/brand name in words induces a high construal level compared to the logo in the picture. 
Figure 1: List of Corporate Brands Utilized in Pre-Test 2

\begin{tabular}{c|c|c|c|c}
\hline Adidas & Coach & KFC & MUFG & Softbank \\
\hline Android & Disney & Lacoste & Nestlé & Starbucks \\
\hline Arena & DreamWorks & Lexus & Nike & Studio Ghibli \\
\hline At\&t & Facebook & McDonald's & Pepsi & Tepco \\
\hline Audi & Hermes & Mercedes-Benz & Red Bull & Timberland \\
\hline Burberry & Honda & Microsoft & Rolex & Toyota \\
\hline Chanel & HSBC & MisterDonut & Shell & Twitter \\
\hline Adidas & Kao & Mos Burger & SMBC & UBS \\
\hline
\end{tabular}

Figure 2: BIF Scale (Japanese Version)

\begin{tabular}{|c|c|c|}
\hline & $\mathbf{A}$ & B \\
\hline Making a list & Getting organized* & Writing things down \\
\hline Reading & Following lines of print & Gaining knowledge* \\
\hline Joining the Army & $\begin{array}{l}\text { Helping the Nation's } \\
\text { defense* }\end{array}$ & Signing up \\
\hline Washing clothes & $\begin{array}{l}\text { Removing odors from } \\
\text { clothes* }\end{array}$ & $\begin{array}{l}\text { Putting clothes into the } \\
\text { machine }\end{array}$ \\
\hline Picking an apple & Getting something to eat* & Pulling an apple off a branch \\
\hline Chopping down a tree & Wielding an axe & Getting firewood* \\
\hline $\begin{array}{l}\text { Measuring a room for } \\
\text { carpeting }\end{array}$ & Getting ready to remodel* & Using a yard stick \\
\hline Cleaning the house & Showing one's cleanliness* & Vacuuming the floor \\
\hline Painting a room & Applying brush strokes & Making the room look fresh* \\
\hline Paying the rent & Maintaining a place to live* & Writing a check \\
\hline Caring for houseplants & Watering plants & Making the room look nice* \\
\hline Locking a door & Putting a key in the lock & Securing the house* \\
\hline Voting & Influencing the election* & Marking a ballot \\
\hline Climbing a tree & Getting a good view* & Holding on to branches \\
\hline Filling out a personality test & Answering questions & Revealing what you're like* \\
\hline Tooth brushing & Preventing tooth decay* & $\begin{array}{l}\text { Moving a brush around in } \\
\text { one's mouth }\end{array}$ \\
\hline Taking a test & Answering questions & Showing one's knowledge* \\
\hline Greeting someone & Saying hello & Showing friendliness* \\
\hline Resisting temptation & Saying "no" & Showing moral courage* \\
\hline Eating & Getting nutrition* & Chewing and swallowing \\
\hline Growing a garden & Planting seeds & Getting fresh vegetables* \\
\hline Traveling by car & Following a map & Seeing countryside* \\
\hline Having a cavity filled & Protecting your teeth* & Going to the dentist \\
\hline Talking to a child & Teaching a child something* & Using simple words \\
\hline Pushing a doorbell & Moving a finger & Seeing if someone's home* \\
\hline
\end{tabular}

*High construal level 


\section{Study 1}

Study 1 aims to investigate the influences of advertising copy and donation magnitude on CRM campaign evaluation and willingness to buy. The study utilized student respondents in the form of a lab experiment. Two forms of advertisement medium (picture vs. word ads) and two types of donation magnitude (5\% vs. $25 \%$ of the selling price) were manipulated. Refer to the pre-test results, Tokyo Disney sea and WWF Japan were used as the test examples for the corporate brand and the charitable organization. In another word, Study 1 adopted a 2 (advertisement medium: words vs. picture) x 2 (donation magnitude: high vs. low) between-subjects factorial design. In particular, respondents were exposed to a poster which detailed the CRM campaign between Tokyo Disney Sea and WWF Japan, either in words or in the picture (refer to Figure 3 and 4). Considering Boenigk and Schuchardt's (2013) study on donation magnitude whereby $1 \%$ of the selling price is considered as low, and $25 \%$ is considered as high, this study decided on $5 \%$ as low and $25 \%$ as high donation magnitudes.

The data collection was divided into five parts. First of all, the respondents filled in their profile information before they were shown the CRM related advertisements (in the form of posters; e.g. A, B, C and D for the four manipulation groups). After viewing the poster for approximately 90 seconds, they were asked to put aside the poster and return to the questionnaire to answer a total of 15 questions measuring attitudes toward the cooperation between the corporate brand and the charitable organization. Next, they were asked to indicate their brand familiarity, willingness to participate and to buy. Finally, two manipulation check questions were asked, upon debriefing.

The real objective of the study was briefed at the end of the test due to the manipulative nature of the study. The translated wordings in the poster stated: "We, Tokyo Disney Sea have launched a limited time special passport. N\% of all sales will be donated to Okinawa Shiraho coral reef conservation activities carried out by the World Wildlife Fund. We support nature protection together with our customers!'” (Refer to Figure 3 and 4). The paragraph was formulated from a collection of ideas from various CRM campaigns, including the statement used by Gucci Japan in Love the Earth Project 21, launched by Fuji TV in 2011. The logos of both companies were not included due to copyright concerns. From a total of 160 respondents, only 129 valid questionnaires were collected (male $=88$, female $=41$ ).

Figure 3: Picture-Based Advertisements with 5\% And 25\% Donation Magnitude
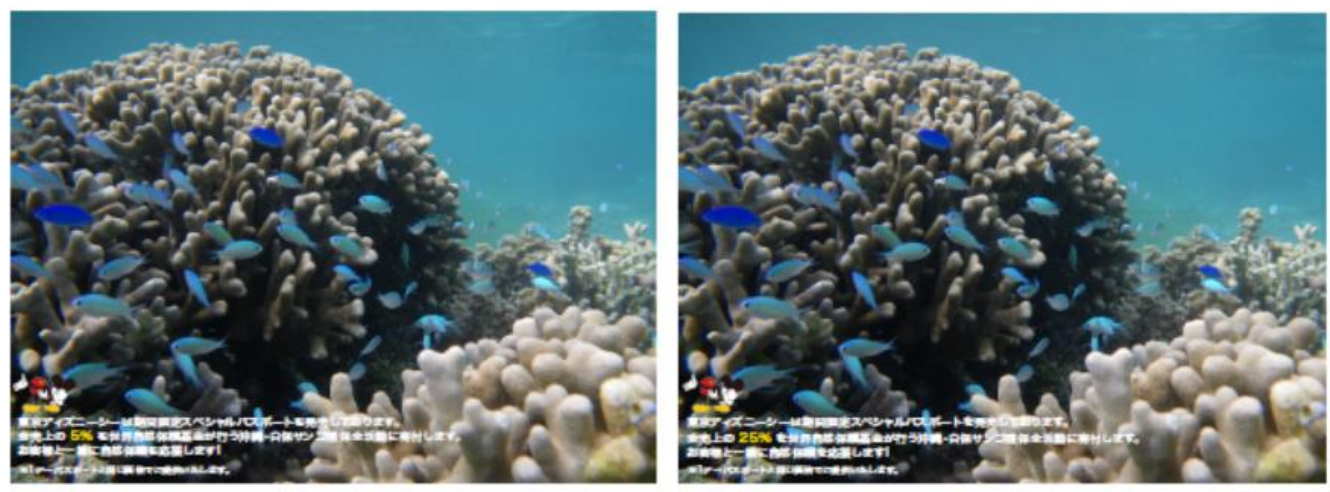
Figure 4: Word-Based Advertisements with 5\% And 25\% Donation Magnitude
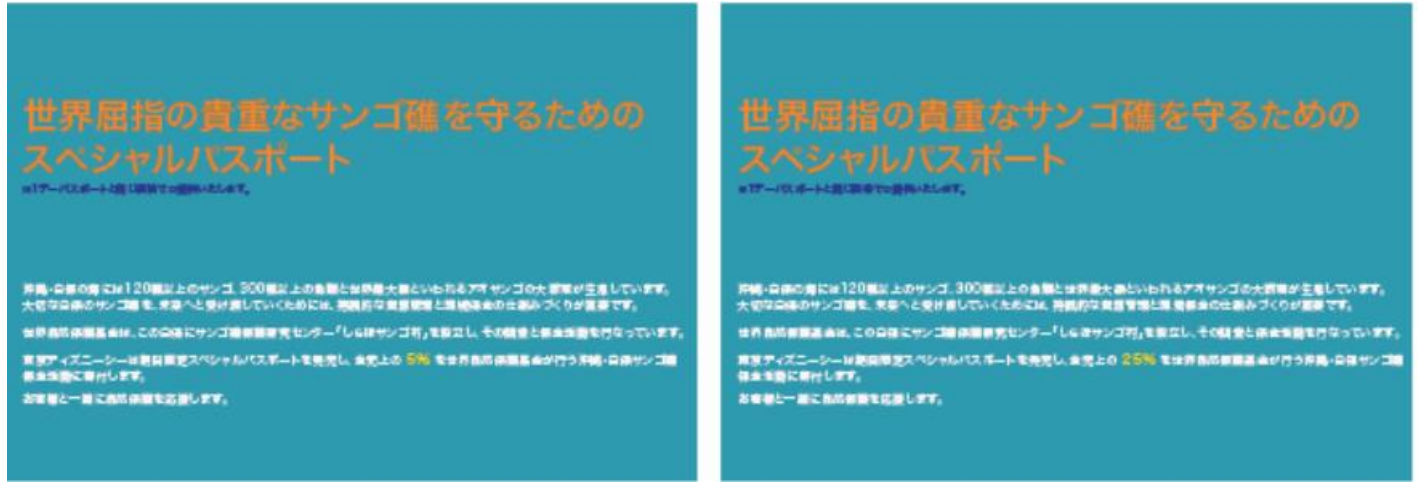

The existing literature suggests the use of a single picture in assessing construal level effects. However, due to the manipulation of donation magnitude, this study had no choice but to use short sentences in the picture-based advertisement (and longer sentences in the word-based advertisement). To enhance the realism of the test, all advertisements adopted the colour scheme used in Finding Nemo, a 2003 Disney Pixar cartoon, in designing the test posters.

This study adopted Desai and Keller (2002), Mitchell and Olson (1981), Nan and Heo (2007), Simonim and Ruth's (1998) 5 item-7point scale for the measurement of attitudes toward the corporate brand and the charity organization. Participation intention was measured by Grau and Folse's (2007) 4 item-7point scale. Finally, consumers' willingness to buy was measured with Yoo and Donthu's (2001) 3 item7 point scale. For manipulation check, respondents were asked to recall and restate the exact amount of donation magnitude mentioned in the earlier part of the questionnaire and whether they considered the donation magnitude as low or high.

From the total 129 valid questionnaires, 63 persons were assigned to group A and $\mathrm{C}$ (5\% donation magnitude); and 66 persons to group $\mathrm{B}$ and $\mathrm{D}$ (25\% donation magnitude). The T-test results indicated a significant difference between the 5\% donation magnitude groups (Mean $=4.41$ ) and the $25 \%$ donation magnitude groups $(\mathrm{M}=5.41), \mathrm{t}(124)=-4.648, \mathrm{p}=.000$. In other words, respondents considered the donation magnitude as low in a $5 \%$ manipulation and high in a $25 \%$ manipulation. The manipulation check was hence successful. The comparison between the four groups indicated that there was a significant difference found between the low donation magnitude groups (group $\mathrm{A}$ and $\mathrm{C}, \mathrm{M}=4.51$ ) and the high donation magnitude groups (group $\mathrm{B}$ and $\mathrm{D}, \mathrm{M}=4.0$ ) in terms of their willingness to buy, $\mathrm{t}(127)=2.358, \mathrm{p}=.02$. This result indicated that people are more willing to buy in a low donation magnitude condition compared to a high donation magnitude condition, which contradicted the proposed hypothesis 1. Hence, H1 was not supported.

From a total of 129 respondents, 66 persons were assigned to the picture-based manipulation (group A and B) and 63 persons to the word-based manipulation (group $\mathrm{C}$ and $\mathrm{D})$. The test results showed that the picture groups $(\mathrm{M}=4.03)$ have a significantly lower willingness to buy than the word groups $(M=4.48), \mathrm{t}(127)=-$ $2.117, p=.036$. In other words, both groups were significantly different in terms of 
their buying intention, with word-based advertisement received a higher evaluation than the picture-based advertisement. The results indicated that people portray different evaluations in response to the choice of advertisement medium, supported hypothesis 2 .

To examine the interaction between construal level and donation magnitude, the results of the 2-way ANOVA indicated significant differences in terms of willingness to buy among the four groups tested, $(1,125)=.735, \mathrm{p}<.05$. Significant main effects were found for both donation magnitude $(F(1,125)=6.069)$ and construal level $(F$ $(1,125)=4.991)$ at $\mathrm{p}<.05$. Next, respondents' willingness to participate and to buy toward the high vs. low donation magnitude and picture vs. word-based manipulations were examined and compared. In a picture-based manipulation, there was no significant influence of donation magnitude on consumers' willingness to participate and to buy, $\mathrm{F}(1,64)=1.276, \mathrm{p}>.01$. Contradictory, in a word-based manipulation, the different levels of donation magnitude have significant influences on consumers' willingness to participate and to buy, $\mathrm{F}(1,61)=5.594, \mathrm{p}<.05$. There were significant main effects for both donation magnitude and construal level, but not the interaction effect. The results did not support the notion that those in a picture-based manipulation were more sensitive to donation magnitude than those in the word-based manipulation. A statistically significant difference in terms of consumers' evaluations toward the CRM campaign was identified in the word-based manipulation. In other words, people are less sensitive to the donation magnitude in a picture vs. word-based manipulations. Hence, hypothesis 3 and 4 were not supported (refer to Figure 5).

\section{Figure 5: Study 1- Consumers' WTP And WTB under Different Donation Magnitude} and Advertisement Copy

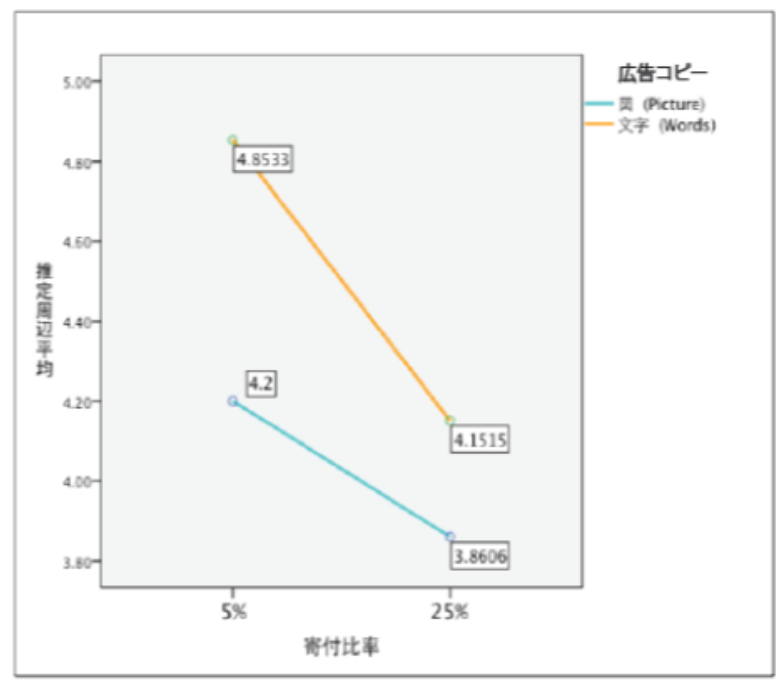

The testing of hypothesis 5 showed that word-based x 5\% donation magnitude group (group C) had the highest evaluation. In addition, there is no significant influence of the donation magnitude in the picture-based manipulation on CRM campaign evaluation. Tukey test was run to compare the different groups to verify further hypothesis 5 (refer to Figure 6). The word-based x 5\% donation magnitude group (group C) was found to be significantly different from the word-based $x 25 \%$ 
donation magnitude group (group D), at $\mathrm{p}<0.1$. This group is also significantly different from the picture-based $\mathrm{x} 25 \%$ donation magnitude group (group B). However, the word-based $\times 5 \%$ donation magnitude group (group C) was not significantly different from the picture-based x 5\% donation magnitude group (group A), $\mathrm{p}=.140$. Based on these results, the word-based x 5\% donation magnitude group scored the highest in willingness to participate and to buy evaluations. Hypothesis 5 was hence cannot be supported. Besides, a significant difference was found between the $5 \%$ donation magnitudes in picture vs. word-based manipulation, at $p<.10$. Even though word-based manipulation generally received higher evaluation than the picture-based, it was not statistically different across the different donation magnitudes.

Figure 6: Study 1 - Comparisons of Willingness to Participate and to Buy Among Four Manipulation Groups

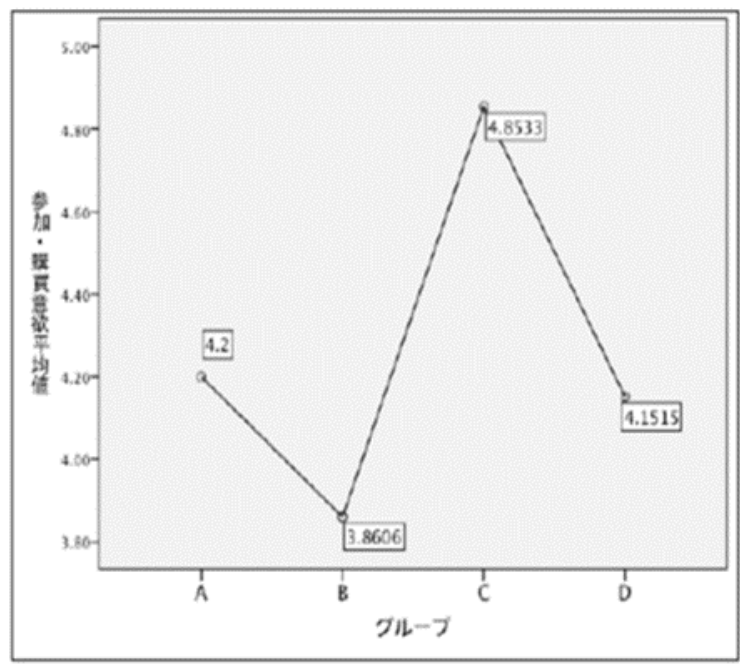

\section{Study 2}

Consistent with Ryoo, Hyun and Sung (2017)'s argument in which results of construal level testing could differ in lab-based and natural settings, Study 2 was carried out to the general public. Similar to Study 1, a 2 (advertisement medium: words vs. picture) x 2 (donation magnitude: low vs. high) between subject factorial design was adopted. Due to the copyright concern, a fictional charitable organization was used (Japan Marine Association) to replace WWF Japan. As a result, parts of the advertisement message were altered (e.g. the corporate brand names and the charitable activities). A total of 300 respondents were collected, with 184 valid questionnaires (Male: 93, Female: 91). The same test procedure as Study 1 was applied.

From a total of 184 valid responses, 95 responses were assigned to $5 \%$ donation magnitude (group and C) and 89 to the $25 \%$ donation magnitude (group B and D). The manipulation check results showed that people who were assigned to 5\% donation magnitude conditions rated the perceived level of donation magnitude (e.g. high or low) significantly lower than those in the $25 \%$ condition, M5\% $=3.71$ vs. $\mathrm{M} 25 \%=4.75$, at $\mathrm{t}(182)=-6.280, \mathrm{p}<.01$. In other words, the manipulation was 
successful, with people in 5\% donation magnitude group considered the donation magnitude was low; while those in $25 \%$ group considered the donation, magnitude was high.

The comparison between the high v. low donation magnitude groups found significant differences, $\mathrm{M} 5 \%=4.26$ vs. $\mathrm{M} 25 \%=3.89$, at $\mathrm{t}(182)=2.086, \mathrm{p}<.05$ in terms of their willingness to buy and participate. In other words, contradicting the original hypothesis, the results showed that people's evaluation tends to be higher (lower) in a low (high) donation magnitude condition. Hence, hypothesis 1 was not supported.

The comparison between the picture vs. word manipulations indicated significant differences (Picture-based, $\mathrm{n}=89$, group $\mathrm{A}$ and $\mathrm{B}, \mathrm{M}=3.77$; word-based, $\mathrm{n}=95$, group and $\mathrm{D}, \mathrm{M}=4.37), \mathrm{t}(164.226)=-3.370, \mathrm{p}<.01$, in terms of their willingness to participate and to buy. In other words, people evaluations toward cause-related marketing differ according to the advertisement medium. In particular, a word-based advertisement was viewed more positively and induced higher willingness to buy and to participate compared to the picture-based advertisement, hence supporting hypothesis 2 .

To verify hypothesis 3 and 4, comparisons were done between the picture-based $\mathrm{x} 5 \%$ donation magnitude $(n=46)$, picture-based $\times 25 \%$ donation magnitude $(n=43)$, wordbased $\times 5 \%$ donation magnitude $(\mathrm{n}=49)$ and lastly, word-based $\times 25 \%$ donation magnitude groups $(n=46)$. A 2-way ANOVA was carried out to compare these four groups and the results showed significant differences between the groups, $F(1,180)=$ $.001, \mathrm{p}>0.1$ (refer to Figure 7). Main effects were found for both donation magnitude $(\mathrm{F}(1,180)=4.591, \mathrm{p}<.05)$ and advertisement medium $(\mathrm{F}(1,180)=11.718, \mathrm{p}<.01)$. Separate one-way ANOVA was conducted to compare the four groups. Donation magnitude was found to have no significant impact on respondents' willingness to participate and to buy in a picture-based advertisement, $\mathrm{F}(1,87)=1.690, \mathrm{p}>.1$; meanwhile, a significant impact was found in the word-based advertisement, $F(1,93)$ $=3.313, \mathrm{p}<.1$. There were significant main effects for both donation magnitude and advertisement medium on willingness to buy and participate. Hence, interaction results cannot be interpreted easily. Similar to Study 1, despite the different advertisement mediums, high vs. low donation magnitudes did not significantly differ in their influences on CRM evaluation. A word-based advertisement was found to have significant differences between the high vs. low donation magnitude at .1 level. In other words, contradicting the original hypothesis, people in the word manipulation were more sensitive to the donation magnitude than those in picture manipulation. Hence, even though hypothesis 3 was not supported, hypothesis 4 was supported at .05 level. 
Figure 7: Study 2- Consumers' WTP and WTB under Different Donation Magnitude \& Advertisement Copy

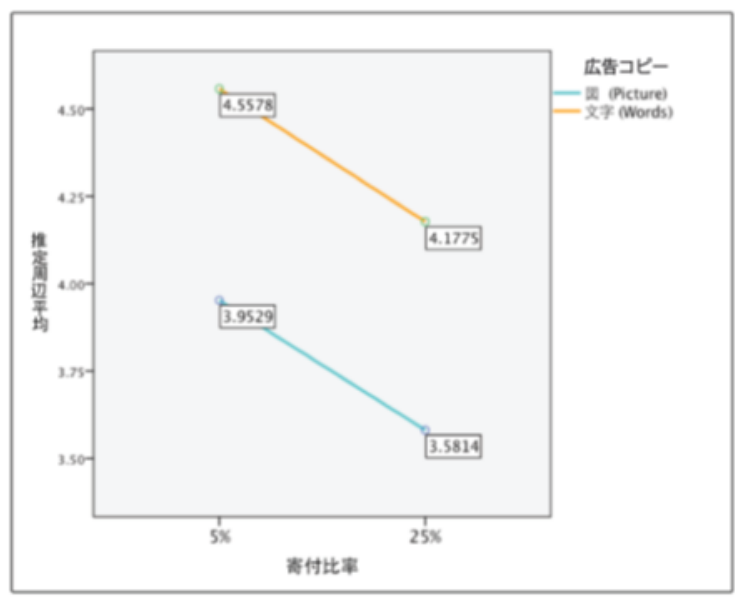

To verify hypothesis 5, the four manipulation groups (picture-based x 5\% donation magnitude, $n=46$; picture-based $\times 25 \%$ donation magnitude, $n=43$; word-based $\times 5 \%$ donation magnitude, $\mathrm{n}=49$; word-based $\mathrm{x} 25 \%$ donation magnitude, $\mathrm{n}=46$ ) were examined. Similar to Study 1, the one-way ANOVA results showed that the word $x$ $5 \%$ donation group received the highest evaluation in terms of willingness to participate and buy, hence not supporting hypothesis 5. The Tukey test further revealed a significant difference between the word-based (group C) and picture-based (group A) manipulations for low donation magnitude groups at $\mathrm{p}<.1$ level. There was also a significant difference between the word-based x 5\% (group $\mathrm{C}$ ) and the picturebased x 25\% (group B) groups, at $\mathrm{p}<.01$ level. Nevertheless, there was no significant difference found between the word-based $\times 5 \%$ (group C) and the word-based x $25 \%$ group (group $\mathrm{D}$ ), $\mathrm{p}=.405$. These results indicated that the word-based $\mathrm{x} 5 \%$ donation magnitude group had the highest evaluation among the four groups, and not supporting hypothesis 5 (refer to Figure 8).

Figure 8: Study 2- Comparisons of Willingness to Participate and to Buy Among Four Manipulation Groups

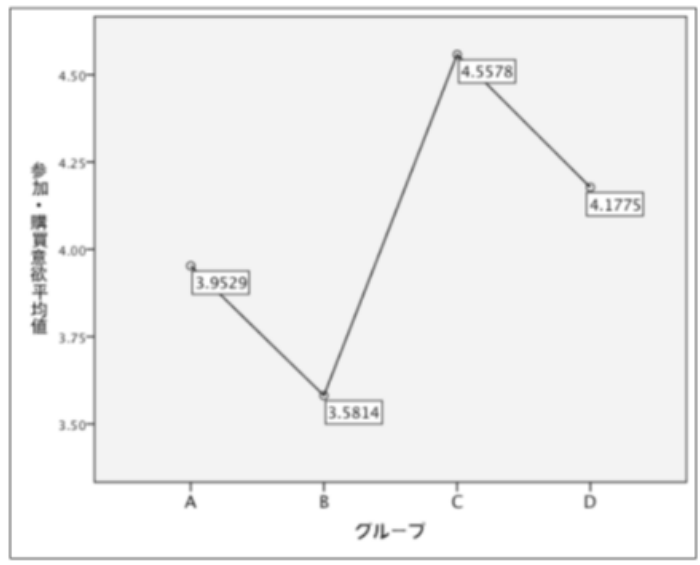




\section{Discussion of Findings}

The findings of both studies provided consistent results, except H4. Hypothesis 1 posits that consumers' evaluation of the CRM campaign should be more positive when the donation magnitude is high. However, by examining consumers' willingness to participate and to buy, a comparison between 5\% and 25\% donation magnitude groups did not reveal statistically significant results in both studies to support hypothesis 1. Contradicting Grau et al. (1997) and Boenigk and Schuchardt's (2013) studies, Japanese consumers did not portray significantly higher evaluation when donation magnitude was high (25\%) compared to when it was low (5\%). A possible explanation of these results could be the culture difference that leads to differences in donation perceptions and habits. Kang et al.'s (2011) study on voluntary activities or donations found a higher tendency for non-participation in the charitable activities among countries with close sovereignty principles such as Japan and South Korea. Japanese are found to be 'tougher donors', with donation per GDP of merely $0.14 \%$ compared to Americans (1.44\%), Britons (0.54\%) and South Koreans (0.5\%; Japan Today, August 3rd, 2019). Japanese traditionally attributed charitable and environment protection activities to the government or company because they viewed individual buying behaviour as less effective (Cones, 2013). In other words, individuals are not used to make personal contributions or donations to charity. In Taniguchi and Marshall (2014)'s study on institutional trust, Japanese society generally has a lower institutional trust and donation is higher only when the institutional trust is high. Contradict Boenigk and Schuchardt (2013), despite the high entrance ticket to Disney, confidence could be lower and Disney's involvement in CRM activities becomes suspicious when the donation magnitude is perceived as high. This result could be unique to the Japanese consumers, contradicted the western studies and hence produced an important contribution to the understanding of Japanese consumers.

Hypothesis 2 examines the impacts of construal level in CRM related advertisement. The Study 1 and 2 results supported hypothesis 2 that the choice of advertisement medium reflects different construal levels, which further influence people willingness to participate and to buy CRM related products, consistent with Kalkstein (2017) and Rim et al. (2015). Word-based advertisement generally received a higher willingness to buy and to participate compared to the picture-based advertisement.

The comparison between donation magnitude and advertisement medium was examined in hypotheses 3 and 4. Contradicting Rim et al. (2015), the results of both studies confirmed that consumers were less sensitive to donation magnitude in a picture vs. word-based advertisements, even when they were instructed specifically to examine the advertisement prior to answering the questionnaires. Also, hypothesis 4 was supported at $p<.05$ level but rejected at $p<.1$ level. The results were rather confusing and contradicting the original hypotheses. It could be attributed to the aforementioned cultural concerns among Japanese consumers or the effect of test design. Respondents' sensitivity to donation magnitude could be differed by the amount of attention paid to donation ratio. Despite the fact that the pre-test result 
supported word-based advertisement to induced high construal as it is written in words and is explaining on "why" the CRM campaign (e.g. to save the environment), Japanese were prompted by the clear and short message content focuses on the gist of the message (Amit et al., 2013), causing the perceived distance to be lower. Due the richness of information in a picture, it is almost impossible to know which details draw more attention (Amit et al., 2013). Different people could have allocated a different amount of time to examine this advertisement (which contains both words and picture) compared to a word-based advertisement. The unfamiliar charitable organization (Japan Marine Association) in Study 2 could explain the inconsistent H4 results, which less familiar name alters the intention to donate in both low and high donation magnitude conditions for picture- and word-based messages. Ryoo et al. (2017) argue in their study on provincial and general norms that people tend to be more affected by things which they perceived as closer to them. In this case, unfamiliar charitable organization names could lead to lesser trust compared to familiar ones (Singh and Duque, 2019), leading to greater sceptical and hence no significant differences between high and low donation magnitude conditions for picture-based message.

The examination of hypothesis 5 indicated a contradicting result to the original hypothesis. The word-based x 5\% donation magnitude group was found to have the highest willingness to participate and to buy the CRM product, rather than the expected $25 \%$ donation magnitude group in both studies. Several possible explanations could be drawn to explain these results. First of all, is the re-examination of donation magnitude effects. In particular, the re-examination of CRM for a hedonic product such as admission tickets to theme parks (e.g. Disneyland). It is possible that consumers hold different perceptions of hedonic vs. functional products in response to CRM related donations. Next, the present study extended the previous study by testing the construal levels for picture vs. words in the advertisement copy and brand logo, rather than just a simple picture or single word, leading to different results produced.

\section{Implications, Conclusions and Limitations}

Despite the popularity of construal level theory, few have examined the relationship between construal levels and donation magnitudes. This study empirically manipulates consumers' construal levels and their donation magnitudes of a CRM campaign, utilizing words- and picture-based advertisement copies and brand logos. First of all, this study successfully manipulated high and low construal levels using words and pictures of corporate logos. Word-based advertisement successfully induces a higher construal level and represents the gist of the campaign better than the picture-based message for an altruistic activity (e.g. CRM campaign). Secondly, the findings also implied that cultural factor could alter the way people look at donation magnitudes, in which low magnitude gains higher trust and preferences consistently across two studies. Thirdly, the findings showed that low donation magnitude and high construal level generate higher intention to donate. Assessment of cultural factor 
in donation magnitude and construal level studies hence calls for further assessment, particularly in countries where a donation to charity is uncommon. Fourth, the effect of construal level and donation magnitude was tested both in a lab setting (Study 1) and natural setting (Study 2), and the results indicate consumers' intention to participate and buy are affected by these two variables.

Several practical implications are worth noting. A word-based message is found to be more advisable than a picture-based message in the product package and advertising designs for CRM campaign. Japanese consumers are found to have a higher willingness to try or to engage in a donation for CRM campaign in a high construal level condition. Provide detailed and solid explanations, and reasons in words about the CRM campaign are viewed as more convincing than pictures, and it is hence more effective to promote altruistic behaviours, consistent with Singh and Duque (2019)'s arguments.

Secondly, a careful selection of donation magnitude in any CRM campaign is essential. Contradicting the western studies, the results implied that a high donation magnitude $(25 \%)$ is viewed with greater distrust in Japan and led to a lower willingness to buy and to participate in a CRM campaign. Meanwhile, a low level of donation magnitude (5\%) is viewed as more realistic and less sceptical. Therefore, the selection of a well-accepted donation magnitude level is of utmost importance in Japanese CRM campaign. The results of our studies indicated that more detailed information about the CRM campaign and a reasonable donation magnitude would work better in convincing the Japanese consumers who are well known for their "no donation culture".

Finally, CRM and CSR activities were found to improve the corporate brand image. CRM helps to build up the institutional trust, especially among the Japanese society, who are more susceptible to organization charitable activities. Therefore, frontier activities such as cultural and technical contributions could help to improve not only the financial status but also the company image. The two empirical studies in this paper produced slightly different results. In Study 1 where a familiar charitable organization (i.e. WWF Japan) was utilized, the decision to participate or to donate has differed across the high vs. low donation magnitudes. Meanwhile, in study 2, the fictitious charitable organization could have led to lesser self-brand relevancy as consumers knew less about this unknown organization. Donation magnitude hence had a lesser role compared to the brand name impact in influencing consumers' willingness to participate and to pay. In the case of Japanese consumers, it was more an issue of how much trust people have in the CRM campaign rather than the influence of the donation magnitude.

There are several limitations to this study. First is the product type issue. The current studies tested on the hedonic product (such as admission tickets to a theme park). Consumers could have gone through different information processing as well as decision-making processes for hedonic and functional products. The next limitation concerns the advertisement design. The unsupported hypotheses in this paper could be 
due to the design of the picture-based advertisement (e.g. a picture with short sentences in explaining the donation magnitude). In order to minimize the effect of the word in measuring the true effect of construal level in CRM studies, a pure picture or illustration advertisement could be more effective. The present study also did not consider the other factors such as personal relevance or "the level of perceived personal importance or interest with cause" (Antil, 1984 in Grau \& Folse, 2007, p. 20) which could lead to different CRM perceptions and participation (Grau \& Folse, 2007). Finally, the current paper did not measure the effect of cultural differences and brand name familiarity. Japanese consumers are found to react differently to the test stimulus, which is inconsistent with western consumers. Comparative studies could be carried out to compare between the far vs. close sovereignty principle countries, and to examine whether this result is only unique to the Japanese consumers.

\section{Practical Implications for Asian Business}

Cause-related marketing has become one of the common concepts in marketing and business discipline over the last decade, and previous research has elucidated that philanthropic activities have increasingly essential in contributing to the short-term and long terms success for the organization. Nonetheless, journal articles rarely give space to discuss cause-related marketing (CRM) in the context of Asia. This holds true for marketers and corporate managers since the problem is especially acute in the Asia context because research on CRM in Asia is still relatively under-developed in comparison to studies from the West. Previous literature has addressed the diversity of customers in Asia compare to the West, and there is a need to change the organizational structure and culture to achieve impactful CRM experience in the context of Asia. Consumer attitudes towards CRM and CSR have been influenced in the West by individual value and lower levels of market intervention and welfare services. However, in Asia, with higher regulation, governments have tended to provide more community services. In addition, with Asian values being more collective, long-term and family-oriented, firm philanthropy introduced by global multinational companies is considered a relatively new phenomenon in the emerging market.

Therefore, it is relevant for companies to study the relative contribution of a specific mix of a social campaign with consumer behaviour and to focus on how construal level and donation magnitude could have affected consumers' attitude and willingness to donate. The current findings provide another alternative perspective to marketers and managers on consumer behaviours towards CRM campaign. In the view of integrated marketing communication, marketers and managers can plan and propose appropriate communication tools to communicate with customers. Types of promotion strategies and approaches can be effectively implemented to cater to the needs of customers based on the distinctive consumer attitude and their reactions to the CRM campaign. For instance, the findings from the current study suggested the usage of word-based advertisement and donation magnitude to increase the willingness to buy and participate from the perspective of the customers in the context 
of Asia. Besides, CRM helps to build up the institutional trust, especially among the societies in Asia who are more susceptible to organization charitable activities.

The findings of the studies added to the understanding of construal level and donation magnitude manipulations in CRM, which benefits both the CRM marketers as well as the business owners. The results of the study indicated that more detailed information about the CRM campaign and a reasonable donation magnitude would work better in convincing the Japanese consumers who are well known for their "no donation culture" to engage in a donation for CRM campaign. Such findings also claimed that consumers did not showcase a consistent evaluation of donation magnitude due to the cultural differences in donation perceptions and habits. In other words, individuals are not used to make personal contribution or donation to charity. In order to remain effective and competitive, managers and marketers must be aware of the mentioned customers' attributes and be able to refine their products to meet diverse needs and wants. Apart from this, the current study has highlighted the importance of CRM to act as an effective sale and marketing approach since consumers will portray a higher intention to buy and to participate in the CRM activities. The usage of construal level theory proposes that people construe things differently based on their perceived psychological distance. Thus, marketers and business owners might obtain better insights in regards to how people think, feel and get motivated from the organization perspective.

\section{References}

Amit, E., Algom, D., \& Trope, Y., (2009), "Distance-dependent processing of pictures and words," Journal of Experimental Psychology, vol. 138, no. 3, pp. 400.

Amit, E., Wakslak, C., \& Trope, Y., (2013), "How do people communicate with others? The effect of psychological distance on preference for visual and verbal means of communication," Personality and Social Psychology Bulletin.

Becker, M., Wiegand, N., \& Reinartz, W. J., (2019), "Does it pay to be real? Understanding authenticity in TV advertising", Journal of Marketing, vol. 83, no. 1, pp. 24-50.

Bennett, C. M., Kim, H., \& Loken, B., (2013), "Corporate sponsorships may hurt non-profits: Understanding their effects on charitable giving," Journal of Consumer Psychology, vol. 23, no.3, pp. 288-300.

Bergkvist, L., \& Zhou, K. Q., (2019), "Cause-related marketing persuasion research: An integrated framework and directions for further research", International Journal of Advertising, vol. 38, no. 1, pp. 5-25.

Boenigk, S., \& Schuchardt, V., (2013), "Cause related marketing campaigns with luxury firms: An experimental study of campaign characteristics, attitudes, and donations", International Journal of Non-profit and Voluntary Sector Marketing, vol. 18, no. 2, pp. 101-121.

Chang, C. T., (2008), "To donate or not to donate? Product characteristics and framing effects of cause related marketing on consumer purchase behaviour," Psychology \& Marketing, vol. 25, no. 12, pp. 1089-1110.

Desai, K. K., \& Keller, K. L., (2002), "The effects of ingredient branding strategies on host brand extendibility," Journal of Marketing, vol. 66, no. 1, pp. 73-93.

Ellen, P. S., Mohr, L. A., \& Webb, D. J., (2000), "Charitable programs and the retailer: Do they mix?", Journal of Retailing, vol. 76, no. 3, pp. 393-406. 
Eyal, T., Liberman, N., \& Trope, Y., (2009), "Psychological distance and consumer behaviour: A construal level theory perspective," The Social Psychology of Consumer Behaviour, pp. 61- 83 .

Eyal, T., Liberman, N., Trope, Y., \& Walther, E., (2004), "The pros and cons of temporally near and distant action," Journal of Personality and Social Psychology, vol. 86, no. 6, pp. 781-795.

Folse, J. A. G., Niedrich, R. W., \& Grau, S. L., (2010), "Cause related marketing:T effects of purchase quantity and firm donation amount on consumer inferences and participation intentions," Journal of Retailing, vol. 86, no. 4, pp. 295-309.

Fujita, K., Eyal, T., Chaiken, S., Trope, Y., \& Liberman, N., (2008), "Influencing attitudes toward near and distant objects," Journal of Experimental Social Psychology, vol. 44, no. 3, pp. 562-572.

Fujita, K., Henderson, M. D., Eng, J., Trope, Y., \& Liberman, N., (2006), "Spatial distance and mental construal of social events," Psychological Science, vol. 17, no. 4, pp. 278282.

Gilead, M., Trope, Y., \& Liberman, N., (2020), "Above and beyond the concrete: The diverse representational substrates of the predictive brain", Behavioural and Brain Sciences, vol. 43, pp. 1-63.

Grau, S. L., \& Folse, J. A. G., (2007), "Cause-related marketing (CRM): The influence of donation proximity and message framing cues on the less involved consumer," Journal of Advertising, vol. 36, no. 4, pp. 19- 33.

Grau, S. L., Garretson, J. A., \& Pirsch, J., (2007), "Cause-related marketing: An exploratory study of campaign donation structures issues," Journal of Non-profit \& Public Sector Marketing, vol. 18, no. 2, pp. 69- 91.

Japan Today, (2019), "Why do Japanese make fewer charitable donations than people in other countries?", Retrieved from: https://japantoday.com/category/features/kuchikomi/whydo-japanese-make-fewer-charitable-donations-than-people-in-other-countries

Kalkstein, D. A., (2017), "Creating expansive learning environments: Abstract thought promotes social learning across psychological distance", Doctoral Dissertation, New York University.

Kang, C., Handy, F., Hustinx, L., Cnaan, R., Brudney, J. L., Haski-Leventhal, D., Holmes, K., Meijs, L., Pessi, A. B., Ranade, B., Smith, K., Yamauchi, N., \& Zrinščak, S., (2011), "What gives? Cross-national differences in students' giving behaviour", The Social Science Journal, vol. 48, no. 2, pp. 283-294.

Kivetz, R., Urminsky, O., \& Zheng, Y. H., (2006), “The goal-gradient hypothesis resurrected: Purchase acceleration, illusionary goal progress, and customer retention", Journal of Marketing Research, vol. 43, no. 1, pp. 39-58.

Liberman, N., \& Trope, Y., (1998), "The role of feasibility and desirability considerations in near and distant future decisions: A test of temporal construal theory", Journal of Personality and Social Psychology, vol. 75, no. 1, pp. 5.

Liberman, N., \& Förster, J., (2009), "Distancing from experienced self: how global versus local perception affects estimation of psychological distance", Journal of Personality and Social Psychology, vol. 97, no. 2, pp. 203-216.

Liberman, N., Sagristano, M. D., \& Trope, Y., (2002), "The effect of temporal distance on level of mental construal", Journal of Experimental Social Psychology, vol. 38, no. 6, pp. 523-534.

Mitchell, A. A., \& Olson, J. C., (1981), "Are product attribute beliefs the only mediator of advertising effects on brand attitude?", Journal of Marketing Research, vol. 18, no. 3, pp. 318-332.

Müller, S. S., Fries, A. J., \& Gedenk, K., (2014), "How much to give?: The effect of donation size on tactical and strategic success in cause-related marketing", International Journal of Research in Marketing, vol. 31, no. 2, pp. 178-191.

Ndasi, W., \& Akcay, E., (2020), "Understanding authenticity in digital cause-related advertising: Does cause involvement moderate intention to purchase?", Westminster Papers in Communication and Culture, vol. 15, no. 2, pp. 24-43. 
Nan, X., \& Heo, K., (2007), "Consumer responses to corporate social responsibility (CSR) initiatives: Examining the role of brand-cause fit in cause-related marketing", Journal of Advertising, vol. 36, no. 2, pp. 63-74.

Olsen, G. D., Pracejus, J. W., \& Brown, N. R., (2003), "When profit equals price: Consumer confusion about donation amounts in cause-related marketing", Journal of Public Policy \& Marketing, vol. 22, no. 2, pp. 170-180.

Pracejus, J. W., \& Olsen, G. D., (2004), "The role of brand/cause fit in the effectiveness of cause-related marketing campaigns", Journal of Business Research, vol. 57, no. 6, pp. 635-640.

Pracejus, J. W., Olsen, G. D., \& Brown, N. R., (2003), "On the prevalence and impact of vague quantifiers in the advertising of cause-related marketing (CRM)", Journal of Advertising, vol. 32, no. 4, pp. 19-28.

Rim, S., Amit, E., Fujita, K., Trope, Y., Halbeisen, G., \& Algom, D., (2015), "How words transcend and pictures immerse: On the association between medium and level of construal", Social Psychological and Personality Science, vol. 6, no. 2, pp. 123-130.

Ross, J. K., Patterson, L. T., \& Stutts, M. A., (1992), "Consumer perceptions of organizations that use cause-related marketing", Journal of the Academy of Marketing Science, vol. 20, no. 1, pp. 93-97.

Ryoo, Y., Hyun, N. K., \& Sung, Y., (2017), "The effect of descriptive norms and construal level on consumers' sustainable behaviours", Journal of Advertising, vol. 46, no. 4, pp. 536-549.

Simonin, B. L., \& Ruth, J. A., (1998), "Is a company known by the company it keeps? Assessing the spill over effects of brand alliances on consumer brand attitudes", Journal of Marketing Research, vol. 35, no. 1, pp. 30-42.

Steckstor, D., (2011), The effects of cause-related marketing on customers' attitudes and buying behaviour, Springer, Germany.

Strahilevitz, M. A., (1999), "The effects of product type and donation magnitude on willingness to pay more for a charity-linked brand", Journal of Consumer Psychology, vol. 8, no. 3, pp. 215-241.

Strahilevitz, M., \& Myers, J. G., (1998), "Donations to charity as purchase incentives: How well they work may depend on what you are trying to sell," Journal of Consumer Research, vol. 24, no. 4, pp. 434-446.

Taniguchi, H., \& Marshall, G. A., (2014), "The effects of social trust and institutional trust on formal volunteering and charitable giving in Japan", International Journal of Voluntary and Non-profit Organizations, vol. 25, no. 1, pp. 150-175.

Trope, Y., \& Liberman, N., (2000), "Temporal construal and time-dependent changes in preference", Journal of Personality and Social Psychology, vol. 79, no. 6, pp. 876.

Trope, Y., \& Liberman, N., (2003), "Temporal construal”, Psychological Review, vol. 110, no. 3, pp. 403-421.

Trope, Y., \& Liberman, N., (2010), "Construal-level theory of psychological distance," Psychological Review, vol. 117, no. 2, pp. 440.

Trope, Y., Liberman, N., \& Wakslak, C., (2007), "Construal levels and psychological distance: effects on representation, prediction, evaluation and behaviour," Journal of Consumer Psychology, vol. 17, no. 2, pp. 83-95.

Vallacher, R. R., \& Wegner, D. M., (1989), "Levels of personal agency: Individual variation in action identification", Journal of Personality and Social Psychology, vol. 57, no. 4, pp. 660.

Van Boven, L., Kane, J., McGraw, A. P., \& Dale, J., (2010), "Feeling close: Emotional intensity reduces perceived psychological distance", Journal of Personality and Social Psychology, vol. 98, no. 6, pp. 872.

Varadarajan, P., (1986), "Horizontal cooperative sales promotion: A framework for classification and additional perspectives", Journal of Marketing, vol. 50, no. 2, pp. 6173. 
Webb, D. J., \& Mohr, L. A., (1998), "A typology of consumer responses to cause-related marketing: From sceptics to socially concerned", Journal of Public Policy \& Marketing, vol. 17, no. 2, pp. 226-238.

Williams, L. E., Stein, R., \& Galguera, L., (2014), "The distinct affective consequences of psychological distance and construal level”, Journal of Consumer Research, vol. 40, no. 6, pp. 1123-1138.

Yan, D., Sengupta, J., \& Hong, J., (2016), "Why does psychological distance influence construal level? The role of processing mode", Journal of Consumer Research, vol. 43, no. 4 , pp. 598-613.

Yoo, D., Kim, J., \& Doh, S. J., (2018), "The dual processing of donation size in CauseRelated Marketing (CRM): The moderating roles of construal level and emoticons", Sustainability, vol. 10, no. 11, pp. 4219.

Yoo, B., \& Donthu, N., (2001), "Developing and validating a multidimensional consumerbased brand equity scale", Journal of Business Research, vol. 52, no. 1, pp. 1-14. 